Table 3 Use of Oral Pregnancy Test in Index and Control Groups

\begin{tabular}{lcc} 
& No test & Test \\
Index & 81 & 19 \\
Control & 96 & 4 \\
$\chi^{2}=9.6$ & \multicolumn{2}{c}{$P=0.01$ to 0.001}
\end{tabular}

partly due to matching the reproductive pattern between the groups.

Differences were found in the number of previous malformed babies and in the history of infertility between the two groups. These cases were excluded to eliminate bias from underlying genetic or other factors, and the result remained significant $(P=0.01$ to 0.001$)$. The high level of significance $(P=<0.001)$ remains when all mothers with all the above predisposing factors were excluded. These results suggest that the pregnancy test might have contributed to, or acted as a trigger factor in, producing the malformation in one in eight of our cases.

The hormonal pregnancy test is used frequently because it is a simple diagnostic procedure and, according to the manufacturers' (Scherings) ${ }^{4}$ earlier description, it is safe because the hormones do not affect the course of pregnancy. However, Scherings $^{5}$ no longer recommend 'Primodos' for diagnosis of pregnancy themselves.

Because the test is usually carried out in a most vulnerable stage of foetal development, there is a possibility of danger to the embryo. In our experiments the average interval between conception and the test was 5.6 weeks in the survey group and 6.2 weeks in the control group.

The possibility of a teratogenic effect of these tablets has been raised and investigated on several occasions. After Dubowitz $^{6}$ reported on a single case in 1962 Smithells $^{7}$ investigated this problem but his survey did not suggest a harmful effect. In 1967, following the paper by Gal et al., the Royal College of General Practitioners conducted a survey which confirmed the possibility of teratological risks when hormones are administered in early pregnancy 8,9 . Nelson's comprehensive study showed a similar trend. Some of these findings may be only of borderline statistical significance but the similarity of the trend in these independent surveys is unlikely to occur by chance.

The pregnancy test works by altering the maternal equilibrium and because the hormonal changes produced by the tablets are sufficiently effective to disturb a non-pregnant uterus, there is a strong possibility that the pregnant one can be affected as well. Bleeding frequently occurs in pregnant women following the test. Dienz and Riese ${ }^{9}$ reported bleeding in $4.6 \%$ of their cases after the administration of 'Duogyon', and Higgins and Sandler ${ }^{10}$ observed it in $10.6 \%$ of women receiving 'Primodos'. According to the Medical Letter Therapeutic Information on Drugs ${ }^{12}$, bleeding occurred in $5 \%$ of pregnant woman. In our survey bleeding occurred in 13 index cases, 3 of whom had the test.

Probably on this consideration hormonal pregnancy tests are frequently used with the very intention of inducing abortion, apparently successfully in susceptible individuals. The Royal College of General Practitioners' Survey into the Outcome of Pregnancy found a $10 \%$ abortion rate after 'Primodos' administration and Brotherton and $\mathrm{Craft}^{12}$ reported an incidence of $7.6 \%$ spontaneous abortion following the use of hormonal pregnancy tests.

It is possible that in less sensitive cases the relatively large dose of hormone in the pregnancy test tablets may interfere with the foeto-placental unit, by upsetting the hormonal balance of the mother, the foetus, or the interaction between them. This may not interrupt pregnancy, but may affect foetal development.

These results indicate the need of fundamental biological studies into the possible harmful effects of hormonal preparation in early pregnancy. Nevertheless, a rigorous statistical analysis has been performed on our data to satisfy those research workers whose assessment of the possible teratogenic effect of an agent is based more on statistical than clinical considerations. Unnecessary risks are being taken by diagnosing pregnancy with an in vivo method when many other reliable in vitro methods are available.

Institute of Obstetrics and Gynaecology,

ISABEL GAL

Queen Charlotte's Maternity Hospital,

Goldhawk Road, London W6

Received November 9, 1971; revised July 27, 1972.

${ }_{1}$ Gal, I., Kirman, B., and Stern, I., Nature, 216, 83 (1967).

2 Laurence, M., Miller, M., Vowles, M., Evans, K., and Carter, C., Nature, 233, 495 (1971).

3 Gal, I., Devl. Med. Child Neurol., Suppl., 15, 86 (1968).

4 Scherings Chemicals Limited, pharmacological description of 'Primodos' (1971).

5 Scherings Chemicals Limited, revised pharmacological description of 'Primodos' (1971).

6 Dubowitz, V., Lancet, ii, 405 (1962).

7 Smithells, R. W., Practitioner, 194, 104 (1965).

${ }^{8}$ Crombie, D., Brit, Med.J., 4, 178 (1970).

9 Dienz, H., and Riese, R., Medshce. Welt, Stuttg., 9, 328 (1956).

10 Higgins, G. L., and Sandler, W. R., Practitioner, 185, 677 (1960).

11 Therapeutic Information on Drugs, Med. Lett., 2, 87 (1969).

12 Brotherton, J., and Craft, I. L., Fert. Steril., 23, 289 (1972).

\section{Reply to Gal}

GAL claims to have implicated hormonal pregnancy test tablets as one of the causes of neural tube malformations. These contain high doses of oestrogens and tend to be administered when one would expect the embryo to be most susceptible. Although on immediate inspection of her evidence, 19 tests in pregnancies ending in central nervous system malformations, with only 4 tests in matched controls, might be reason for casting suspicion on these hormone tests, a note of caution should be sounded. First, the choice of controls was unfortunate for while index cases were drawn from a wide area of Southern England, matched controls were chosen from women attending one hospital only. The difference found could be due entirely to local differences in prescribing practices. Indeed, that the controls were perhaps inappropriate in other respects too is suggested by another study by $\mathrm{Gal}$ and her co-workers ${ }^{1}$ when in an investigation into the possible role of Vitamin A deficiency in the genesis of central nervous system malformation, a significant relationship was demonstrated when the self-same controls were used, which all but disappeared when controls were selected from the individual hospitals where the malformed child was born. Second, it is well known in epidemiological studies that when a number of different factors are related to a medical event that one or more may be related at say a 1 in 100 level of significance. The suggested relationship should, however, always be re-examined by a second run before it is accepted. Both these objections are underlined by a study of the hormone tests in South Wales by Laurence and his co-workers (ref. 2 and personal communication) where on the one hand it was noted that practitioners in one area but not in another frequently used the test, and on the other hand, that no significant difference between the test frequency in index and control pregnancies was found, and were thus unable to confirm Gal's findings. In any case, epidemiological data during the last 30 years would not be in accordance with such an aetiology for the neural tube abnormalities.

It is therefore unlikely that either the hormone pregnancy test or Vitamin A deficiency play a significant part in the genesis of central nervous system malformations.

K. M. LAURENCE

Child Health Laboratories, Department of Child Health, Welsh National School of Medicine, Llandough Hospital, Penarth, Glamorgan CF6 1 XX

Received November 14, 1972.

${ }^{1} \mathrm{Gal}$ et al., Advances in Teratology, 5, 144 (edit. by Woolam, D. H. M.) (Logos Press, London, 1972).

2 Laurence et al., Nature, 233, 495 (1971). 